\title{
Critical care management of pulmonary arterial hypertension in pregnancy: the pre-, peri- and post- partum stages
}

\author{
Vorakamol Phoophiboon ${ }^{1,2}$, Monvasi Pachinburavan ${ }^{1,2}$, Nicha Ruamsap ${ }^{3}$, Natthawan Sanguanwong ${ }^{3,4}$, \\ Nattapong Jaimchariyatam ${ }^{3,4}$
}

${ }^{1}$ Division of Critical Care Medicine, Department of Medicine, Faculty of Medicine, Chulalongkorn University, Bangkok; ${ }^{2}$ Excellence Center for Critical Care Medicine, King Chulalongkorn Memorial Hospital, Thai Red Cross Society, Bangkok; ${ }^{3}$ Division of Pulmonary and Critical Care Medicine, Department of Medicine, Faculty of Medicine, Chulalongkorn University, Bangkok; ${ }^{4}$ Excellence Center for Sleep Disorder, King Chulalongkorn Memorial Hospital, Thai Red Cross Society, Bangkok, Thailand

The mortality rate of pulmonary hypertension in pregnancy is $25 \%-56 \%$. Pulmonary arterial hypertension is the highest incidence among this group, especially in young women. Despite clear recommendation of pregnancy avoidance, certain groups of patients are initially diagnosed during the gestational age step into the third trimester. While the presence of right ventricular failure in early gestation is usually trivial, it can be more severe in the late trimester. Current evidence shows no consensus in the management and serious precautions for each stage of the pre-, peri- and post-partum periods of this specific group. Pulmonary hypertension-targeted drugs, mode of delivery, type of anesthesia, and some avoidances should be planned among a multidisciplinary team to enhance maternal and fetal survival opportunities. Sudden circulatory collapse from cardiac decompensation during the peri- and post-partum phases is detrimental, and mechanical support such as extracorporeal membrane oxygenation should be considered for mitigating hemodynamics and extending cardiac recovery time. Our review aims to explain the pathophysiology of pulmonary arterial hypertension and summarize the current evidence for critical management and precautions in each stage of pregnancy.

Key Words: extracorporeal membrane oxygenation; heart decompensation; pregnancy; pulmonary arterial hypertension; right-sided heart failure; vasodilator agents

\section{INTRODUCTION}

Pulmonary arterial hypertension (PAH) often leads to acute right ventricular failure, circulatory collapse and death during in pregnancy [1,2]. The incidence of PAH in pregnancy has ranged from less than $1 \%$ to $8 \%$, and maternal mortality $(9 \%-33 \%)$ is highest among pregnancies coexisting with cardiac disease [3-6]. The manifestations of undiagnosed PAH during pregnancy are difficult to distinguish from the normal physiologic changes of pregnancy, such as palpitations, exertional dyspnea and lower extremity edema [7]. When the symptoms of right ventricular failure are detected late in these patients, the appropriate treatment is delayed $[8,9]$. The hemodynamic changes during the peri- and post-partum pe-

\section{Review Article}

Received: April 10, 2021

Revised: July 7, 2021

Accepted: August 31, 2021

Corresponding author

Vorakamol Phoophiboon

Division of Critical Care Medicine,

Department of Medicine, Faculty of

Medicine, Chulalongkorn University,

1873 Rama 4 Rd, Pratumwan,

Bangkok 10330, Thailand

Tel: +66-98-989-9214

E-mail: rakamol@hotmail.com

Copyright (C) 2021 The Korean Society of Critical Care Medicine

This is an Open Access article distributed under the terms of Creative Attributions Non-Commercial License (https:// creativecommons.org/li-censes/by-nc/4.0/) which permits unrestricted noncommercial use, distribution, and reproduction in any medium, provided the original work is properly cited. 
riods cause the majority of maternal morbidity and mortality as a result of increased cardiac output [10]. In this particular context, cardiac decompensation consists of acute right ventricular failure, cardiogenic shock, and cardiac collapse. Referral to a pulmonary hypertension center that uses a multidisciplinary team approach (obstetrician, cardiologist, pulmonologist, anesthesiologist, cardio-thoracic surgeon, intensivist, and pediatrician) should be considered as necessary to improve outcomes.

\section{PATHOPHYSIOLOGY OF CARDIAC DECOMPENSATION IN PREGNANT PATIENTS WITH PAH}

\section{Pre-partum Stage}

In 2nd to 3rd trimester of gestation, a normal physiologic change contributes to surging cardiac output as a result of increased stroke volume, heart rate and total blood volume. The maternal blood volume rises approximately $45 \%$ (1,200 to 1,600 $\mathrm{ml}$ ) with the highest in the 3rd trimester (32-34 weeks) [7,11]. The gestational hormones estrogen and progesterone are produced by the placenta and have a vasodilator effect through membranous ion channels, relating to decreased systemic vascular resistance (SVR) and pulmonary vascular resistance (PVR) [12-14]. Recorded by transthoracic echocardiography (TTE), PVR reduction is mostly in the third trimester by $17.5 \%$ [7]. The effect of low SVR and PVR during pregnancy mitigates cardiac decompensation in $\mathrm{PAH}$ patients from high cardiac output. However, the effect of vasodilation incompletely ameliorates the detrimental result from right ventricular failure when patients enter the last trimester. The late 2nd to 3rd trimester and postpartum are the two critical phases of cardiac decompensation in pregnant patients with $\mathrm{PAH}$ [15]. In addition, physiologic anemia during pregnancy and hormonal effect decrease myocardial oxygen supply, contributing to right ventricular wall stress and remodeling (Figure 1) [16].

\section{Peri-partum Stage}

During labor, the cardiac output and systemic blood pressure rise with each uterine contraction [17], and auto-transfusion returns of 300-500 $\mathrm{ml}$ of blood into the systemic circulation. The sympathetic response to pain and anxiety also elevates maternal blood pressure and heart rate [11]. The overwhelming venous return and rising systemic resistance directly affect right ventricular function. The prolong secondary stage of labor and the Valsalva maneuver are known as negative risk

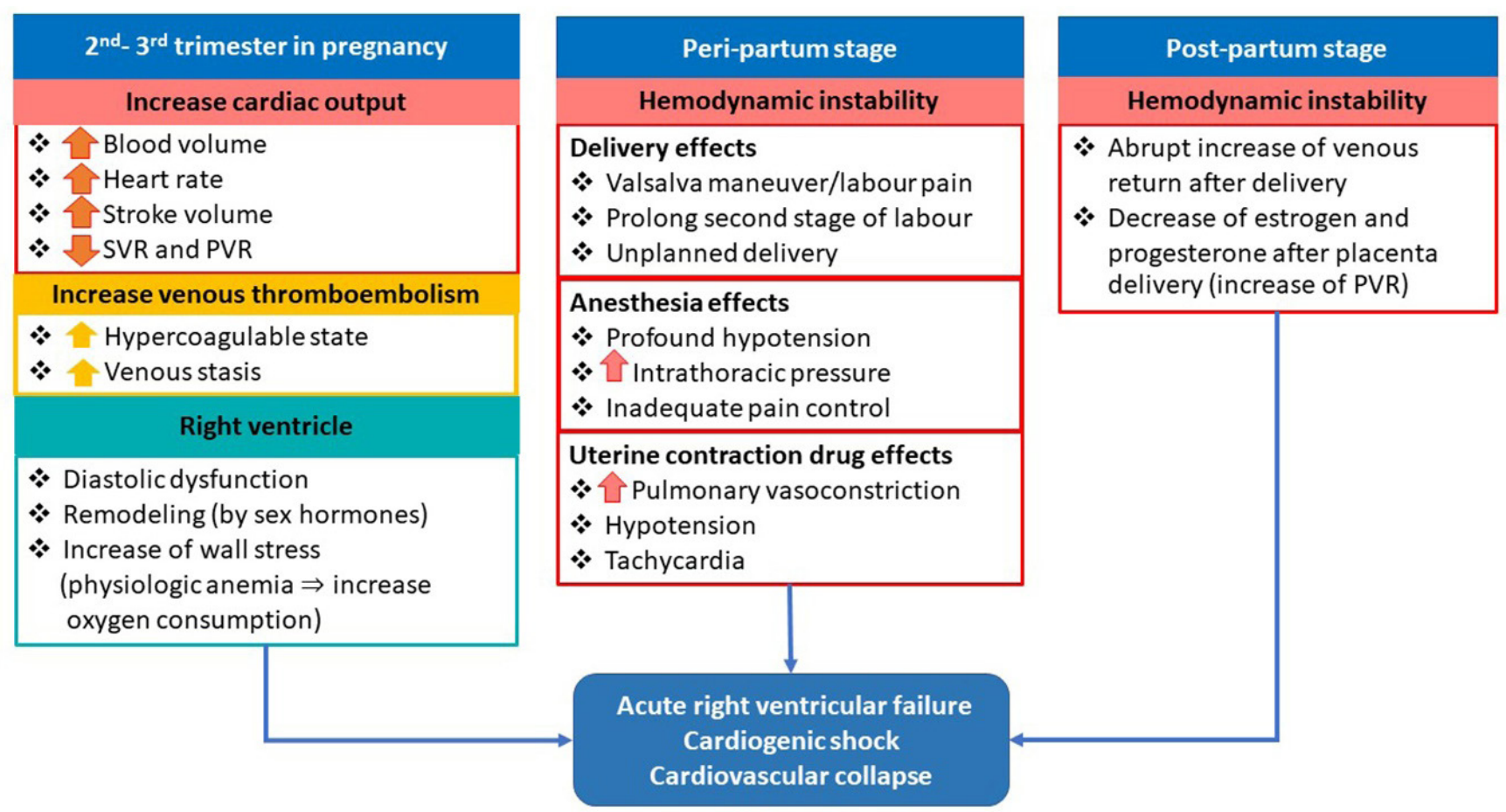

Figure 1. Pathophysiology of acute right ventricular failure, cardiogenic shock, and cardiovascular collapse in pregnant patients with pulmonary arterial hypertension (PAH) during the pre-, peri- and post-partum stages. SVR: systemic vascular resistance; PVR: pulmonary vascular resistance. 
factors [18] as well as anesthetic methods due to the increased intrathoracic pressure and PVR. These effects predispose to acute right ventricular failure and profound hypotension.

\section{Post-partum Stage}

After delivery, an abrupt increase of venous return (500 ml) from inferior vena cava decompression returns to the heart, resulting in decompensation of an unhealthy right ventricle $[11,15]$. In addition, a fall of estrogen and progesterone levels after placenta delivery directly affects the pulmonary venous resistance. An abrupt rise of pulmonary venous resistance obscures fluid flow from right-to-left circulation, leading to cardiac decompensation.

\section{CRITICAL CARE MANAGEMENT OF CARDIAC DECOMPENSATION IN PREGNANT PATIENTS WITH PAH}

\section{Pre-partum Stage}

PAH-targeted therapy

A pulmonary vasodilator, which reduces right ventricular afterload and improves cardiac function, is an important treatment of PAH [19]. There are three main mechanisms of PAH treatment: cyclic adenosine monophosphate, cyclic guanosine monophosphate and endothelin pathway [20]. However, the endothelin receptor antagonist group is a contraindication in pregnancy due to its teratogenic effects (category X). The following drugs are commonly administered in pregnancy. (1) Cyclic adenosine monophosphate pathway: (a) inhaled nitric oxide (iNO), (b) phosphodiesterase 5 inhibitor; sildenafil (category B) is commonly used in combination with prostaglandin, (c) guanylate cyclase stimulator is category $\mathrm{X}$.
(2) Cyclic guanosine monophosphate pathway: (a) prostacyclin derivatives; intravenous epoprostenol, inhaled iloprost.

The severity of patients who haven't received treatment is classified by the World Health Organization functional classification (WHO FC) I to IV. Patients with WHO FC I-II should be treated with oral sildenafil and closely monitored, while WHO FC III-IV patients require hospital admission and administration of either intravenous prostacyclin derivatives or combined therapy (Table 1).

\section{Close monitoring}

In the pre-delivery stage, TTE should be used for daily monitoring to detect early cardiac decompensation and evaluate fluid status. An arterial line and a central venous catheter can also be considered for hemodynamic monitoring, while a pulmonary artery catheter is not routinely required.

\section{Anticoagulant}

Due to their hypercoagulable state, these patients have a high risk of venous thromboembolism as acute pulmonary embolism and deep vein thrombosis during both pregnancy and the post-postpartum period [21]. As a result of increased estrogen levels, blood coagulation Factors 7, 8, 9, 10, 12, 13 and von Willebrand factor are markedly elevated, which significantly increases in the third trimester [11]. Additionally, the increased levels of several plasminogen inhibitors diminish the overall fibrinolytic capacity $[22,23]$. While blood coagulation inhibitors are unpredictable, their effects during pregnancy result in unchanged antithrombin and protein $\mathrm{C}$ levels and a markedly decreased protein $\mathrm{S}$ level. The reduction of venous flow in the lower limbs is another precipitating risk [11]. Consequently, it is recommended that PAH patients

Table 1. WHO FC-related PAH-targeted drugs in pregnancy

\begin{tabular}{|c|c|c|c|c|}
\hline Severity WHO FC & Type of medication & Route & Dosage & Pregnancy category \\
\hline $\mathrm{FCI}-\mathrm{II}$ & $\begin{array}{l}\text { Phosphodiesterase } 5 \text { inhibitor: } \\
\text { sildenafil }\end{array}$ & Oral & 20-150 mg/day [24] & B \\
\hline FC III & Prostacyclin derivative: iloprost & Inhaled (ultrasonic nebulizer) & 3-20 $\mu \mathrm{g} /$ day (7-9 times/day) [25] & C \\
\hline \multirow[t]{4}{*}{ FC IV } & Prostacyclin derivative: epoprostenol & Intravenous & $\begin{array}{l}\text { Initiate at } 2 \mathrm{ng} / \mathrm{kg} / \mathrm{min} \text { and gradually increase } \\
\text { up to } 20 \mathrm{ng} / \mathrm{kg} / \mathrm{min} \text { [26] (maximally tolerated } \\
\text { dosage based on clinical symptoms and } \\
\text { adverse effects) }\end{array}$ & B \\
\hline & May combine with sildenafil [27] & & & \\
\hline & Nitric oxide & Inhaled & 5-20 PPM [28] & C \\
\hline & May combine with sildenafil [29] & & & \\
\hline
\end{tabular}

WHO: World Health Organization; FC: functional classification; PAH: pulmonary arterial hypertension. 
with pregnancy in the antepartum through postpartum periods should be treated with low molecular weight heparin $[2,9,30,31]$. Unfractionated heparin should also be considered, especially in the unpredictable peri-partum phase.

\section{Peri-partum Stage}

Mode of delivery: vaginal delivery vs. caesarean section The gestation of 32 to 36 weeks is preferable for delivery $[1,9]$ because of its many advantages, such as accessibly promoting fetal lung growth, absence of uterine contraction and wellplanned delivery. Cardiac stabilization with an adequate PAH-targeted therapy and resuscitation are necessary to reduce maternal and fetal mortality. The mode of delivery between vaginal delivery (the previous decade) and caesarean section (the present) remains controversial [31,32]. Although the benefits of vaginal delivery consist of smaller blood volume loss, lower bleeding complication, lower infection rate, and less altered hemodynamics than caesarean section [9,33,34], it has some serious complications. First, labor pain could overstimulate the sympathetic nervous system. Second, the Valsalva effect during delivery could worsen maternal cardiac function due to low cardiac output by increasing intrathoracic pressure and thus decreasing venous return [35]. Currently, elective caesarean section is considered as a mode of delivery due to better control of hemodynamic outcomes and delivery duration $[3,36,37]$.

Anesthetic management: regional anesthesia vs. general anesthesia

There are many adverse effects from general anesthesia, especially increases of pulmonary arterial pressure and PVR during laryngoscopy and tracheal intubation. In addition, the positive pressure ventilation on venous return may lead to hemodynamic instability $[3,38]$. Regional anesthesia is commonly used by combining the spinal and epidural approach to provide ultimately effective anesthesia to minimize the dose of anesthetics [39]. Epidural anesthesia has a slow onset (15-20 minutes) but provides hemodynamic stability. In contrast, spinal anesthesia is rapid onset (1-2 minutes) but is associated with peripheral vasodilation. However, single-shot spinal anesthesia should be avoided because of its profoundly hemodynamic effect by sympathetic block [31]. Furthermore, the ultimate goal of anesthetic management is the control of pain, where hypoxemia and hypercapnia could be considered as hemodynamically sustaining effects $[19,40]$.

\section{Uterine contraction agents}

The uterine contraction agent is a potential risk for deteriorating the circulatory system, although it can be necessary for the prevention of uterine atony [32]. In PAH patients, oxytocin should be given by infusion without a bolus dose to reduce systemic vasodilation. A slow infusion rate of oxytocin effectively minimizes the potential for hypotension, tachycardia, and fluid retention [41]. Ergotamine and prostaglandin F2 alpha should be cautiously used in PAH patients because of their effects to increase vasoconstriction, myocardial infarction and pulmonary venous congestion [15].

\section{Post-partum Stage}

\section{Close monitoring in the intensive care unit}

The majority of deaths in pregnant patients with PAH in the last decade have occurred in the post-partum period, mainly in the first to third month [31,42,43]. Most observational studies illustrated unprecedented events, such as severe right ventricular failure, hypotension, and circulatory collapse, which occurred within the first 7 days after delivery [1]. The treatment goals during the post-partum period, especially in the first 48 hours, are to avoid volume overload, maintain systemic blood pressure and closely observe right atrial pressure and cardiac function.

Medical management during cardiac decompensation Drugs used to treat right heart failure are mostly in the Food and Drug Administration (FDA) pregnancy category C except dobutamine (category B). Fortunately, most pregnant patients with PAH develop cardiac decompensation after delivery because of the pathophysiology of increased venous return and PVR. Therefore, the treatment of right heart failure and cardiogenic shock is not significantly different from the non-pregnant group. However, the treatment of unhealthy right ventricular function and PAH largely deals with the preload sensitive character (i.e., avoiding over-corrected fluid or over diuresis), reduction in PVR as previously mentioned (optimizing afterload), and contractility promotion. The role of diuresis (furosemide is FDA pregnancy category C) may be essential in patients who have obvious pulmonary edema, and close monitoring is required. The increase of right ventricular contractility with inotropic agents has been proposed in various studies; however, there are some commonly used treatments in right heart failure that have smaller effects on the increased PVR, such as milrinone, dobutamine, and levosimendan [44-46]. In a hypotensive patient, either epinephrine or norepinephrine is 

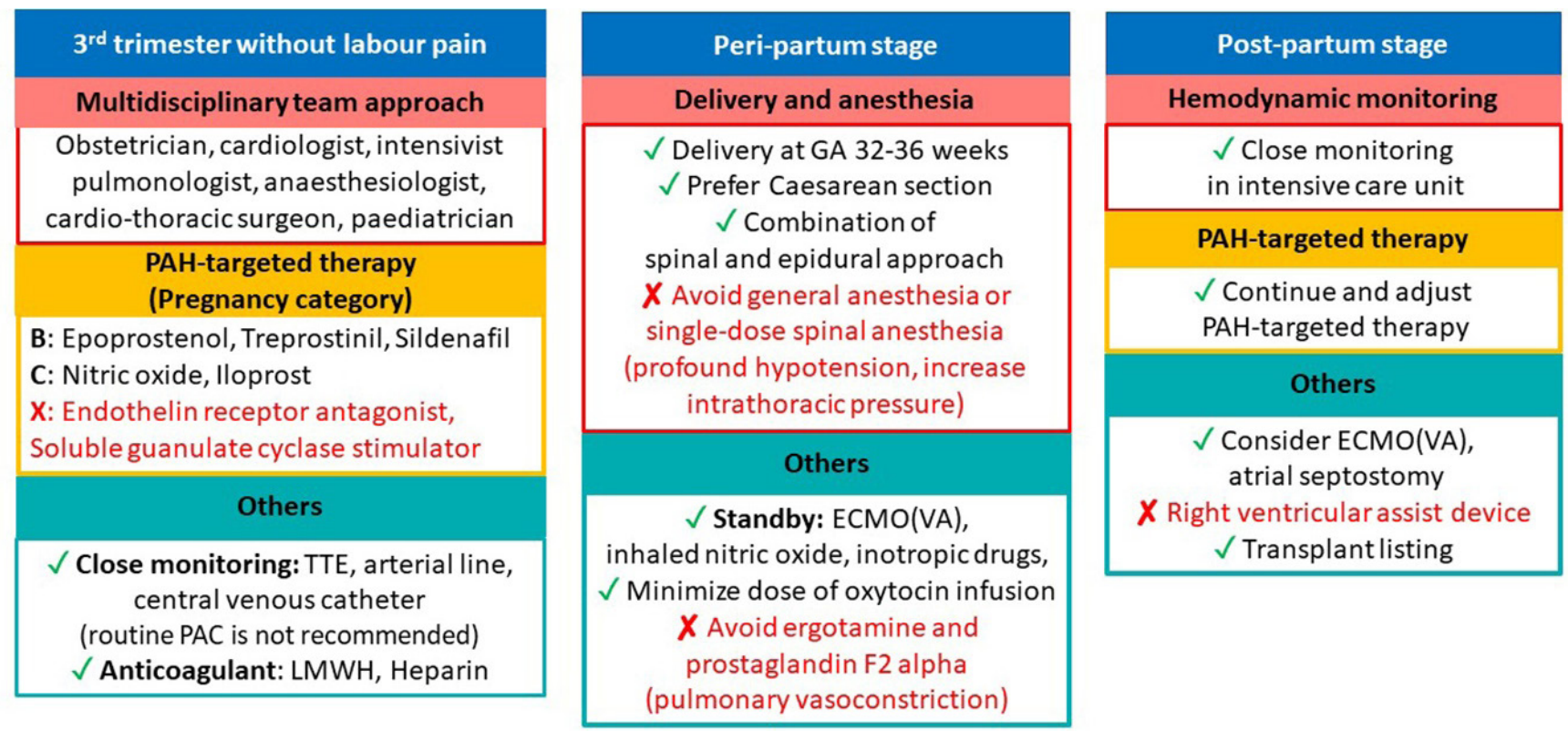

Figure 2. Critical care management for acute right ventricular failure, cardiogenic shock and cardiovascular collapse in pregnant patients with pulmonary arterial hypertension (PAH) during the pre-, peri- and post-partum stages. TTE: transthoracic echocardiography; LMWH: low molecular weight heparin; ECMO: extracorporeal membrane oxygenation; VA: veno-arterial.

preferable to add-on with minimally increased PVR concerns $[47,48]$.

\section{Rescue management}

In a PAH patient who is unresponsive to maximal medical therapy, extracorporeal membrane oxygenation (ECMO) is a novel mechanical support for bridging to recovery or transplantation by unloading the right ventricle and enhancing oxygenation and ventilation $[18,49]$. While right ventricular assist device mainly supports right ventricular load without improving oxygenation and ventilation, it carries a potential to rupture the pulmonary artery. There is no current guideline on the use of ECMO during or after pregnancy [50]. The initial ECMO configurations reported in pregnancy are veno-venous, veno-arterial (VA) and veno-arterial-venous mode. However, VA-ECMO is widely considered to support hemodynamics in decompensated pregnant $\mathrm{PAH}$ patients, and some are extubated while continuing VA-ECMO. Although ECMO is one of the supporting procedures for recovery, time mostly being activated that was in postpartum period when refractory circulatory failure usually occurred. Several reports showed some benefits of ECMO during the peripartum stage $[24,25,27,37,43,51]$. Cannula size and route are also challenging for cannulation due to the anatomical changes during pregnancy. Femoral cannulation should be performed with caution, but there have been no reports of flow insufficiency from gravid uterus compression $[26,43]$. The duration of ECMO has been reported from 6 to 30 days, and bleeding is the most common complication [29,43]. Alternatively, atrial septostomy may be an additional method for unloading right ventricular pressure and particularly early promoting ECMO decannulation [29].

\section{Contraception}

Pregnancy is classified by the WHO in category 4 as an extremely high risk of maternal morbidity and mortality, which is an absolute contraindication of pulmonary hypertension patient [28]. Termination should be discussed if it is plausible. The current practice is focusing on outpatient counselling for pregnancy prevention, as there are many issues surrounding methods of contraception [52]. Currently, estrogen-containing contraceptives and injectable progestins are not recommended because of their potentially increased risk of venous thromboembolism, while the progestin-only pill often has a high failure rate of contraception [35,53]. Alternatively, non-permanent devices, such as progestin-only intrauterine device and implantation, are acceptable, but they have imprecise efficacy and could alter levels of pulmonary vasodilator drugs. Consequently, permanent contraception is preferable. A report from the Mayo Clinic of a retrospective cohort showed that micro-insert hysteroscopic sterilization provided an effective 
advantage in patients who could undergo the procedure in an elective setting due to its small procedural risk [54]. Laparoscopic tubal ligation still requires general anesthesia [35]. Tubal ligation, however, could be performed in patients who underwent caesarean section (Figure 2).

\section{CONCLUSION}

The presence of PAH with pregnancy in the 3rd trimester leads to unavoidable morbidity or mortality. Acute right ventricular decompensation usually demonstrates either near the end of gestation or in the post-partum period. The critical care management should consist of pulmonary hypertension-targeted treatment, mode of delivery, anesthesia, and postoperative care after delivery, including promoting cardiac function with medications, rescuing therapies, and a multidisciplinary team approach to promote good maternal and fetal outcomes. Effective permanent contraception is essentially required in patients with PAH who are of childbearing age for the prevention of devastating events.

\section{CONFLICT OF INTEREST}

No potential conflict of interest relevant to this article was reported.

\section{ACKNOWLEDGMENTS}

We would like to thank the Division of Pulmonary and Critical Care Medicine, Department of Medicine, Faculty of Medicine, Chulalongkorn University, Bangkok, Thailand for administrative support and assistance.

\section{ORCID}

Vorakamol Phoophiboon

https://orcid.org/0000-0001-5461-9448

Nattapong Jaimchariyatam

https://orcid.org/0000-0003-4904-6715

\section{AUTHOR CONTRIBUTIONS}

Conceptualization: VP, MP, NP. Data curation: VP, MP, NS, NJ. Formal analysis: VP, NP. Funding acquisition: VP, NJ. Methodology: VP. Project administration: VP. Visualization: VP, MP. Writing-original draft: VP, NP, NS. Writing-review \& editing: all authors.

\section{REFERENCES}

1. Bédard E, Dimopoulos K, Gatzoulis MA. Has there been any progress made on pregnancy outcomes among women with pulmonary arterial hypertension? Eur Heart J 2009;30:256-65.

2. Olsson KM, Jais X. Birth control and pregnancy management in pulmonary hypertension. Semin Respir Crit Care Med 2013;34:681-8.

3. Martínez MV, Rutherford JD. Pulmonary hypertension in pregnancy. Cardiol Rev 2013;21:167-73.

4. Roos-Hesselink J, Baris L, Johnson M, De Backer J, Otto C, Marelli A, et al. Pregnancy outcomes in women with cardiovascular disease: evolving trends over 10 years in the ESC Registry Of Pregnancy And Cardiac disease (ROPAC). Eur Heart J 2019;40:3848-55.

5. Yang M, Wang J, Zhang X, Zhuang Q, Wang R, Shen J, Lin J. Incidence and long-term outcomes of pregnant women complicated with pulmonary arterial hypertension during different pregnancies: a prospective cohort study from China. Int J Cardiol 2021;326:178-83.

6. Yang JZ, Fernandes TM, Kim NH, Poch DS, Kerr KM, Lombardi S, et al. Pregnancy and pulmonary arterial hypertension: a case series and literature review. Am J Obstet Gynecol MFM 2021;3:100358.

7. Sharma R, Kumar A, Aneja GK. Serial changes in pulmonary hemodynamics during pregnancy: a non-invasive study using doppler echocardiography. Cardiol Res 2016;7:25-31.

8. Madden BP. Pulmonary hypertension and pregnancy. Int J Obstet Anesth 2009;18:156-64.

9. Olsson KM, Channick R. Pregnancy in pulmonary arterial hypertension. Eur Respir Rev 2016;25:431-7.

10. Hall ME, George EM, Granger JP. The heart during pregnancy. Rev Esp Cardiol 2011;64:1045-50.

11. Soma-Pillay P, Nelson-Piercy C, Tolppanen H, Mebazaa A. Physiological changes in pregnancy. Cardiovasc J Afr 2016;27: 89-94.

12. Smith AM, Jones RD, Channer KS. The influence of sex hormones on pulmonary vascular reactivity: possible vasodilator therapies for the treatment of pulmonary hypertension. Curr Vasc Pharmacol 2006;4:9-15.

13. Christou HA, Khalil RA. Sex hormones and vascular protection in pulmonary arterial hypertension. J Cardiovasc Pharmacol 2010;56:471-4.

14. English KM, Jones RD, Jones TH, Morice AH, Channer KS. Gen- 
der differences in the vasomotor effects of different steroid hormones in rat pulmonary and coronary arteries. Horm Metab Res 2001;33:645-52.

15. Burt CC, Durbridge J. Management of cardiac disease in pregnancy. Contin Educ Anaesth Critic Care Pain 2009;9:44-7.

16. Neema PK. Eisenmenger syndrome: an unsolved malady. Ann Card Anaesth 2012;15:257-8.

17. Hsu CH, Gomberg-Maitland M, Glassner C, Chen JH. The management of pregnancy and pregnancy-related medical conditions in pulmonary arterial hypertension patients. Int J Clin Pract Suppl 2011;(172):6-14.

18. Kumar A, Neema PK. Severe pulmonary hypertension and right ventricular failure. Indian J Anaesth 2017;61:753-9.

19. Bassily-Marcus AM, Yuan C, Oropello J, Manasia A, Kohli-Seth $\mathrm{R}$, Benjamin E. Pulmonary hypertension in pregnancy: critical care management. Pulm Med 2012;2012:709407.

20. Huang S, DeSantis ER. Treatment of pulmonary arterial hypertension in pregnancy. Am J Health Syst Pharm 2007;64:1922-6.

21. Franchini M. Haemostasis and pregnancy. Thromb Haemost 2006;95:401-13.

22. Hellgren M. Hemostasis during normal pregnancy and puerperium. Semin Thromb Hemost 2003;29:125-30.

23. Szecsi PB, Jørgensen M, Klajnbard A, Andersen MR, Colov NP, Stender S. Haemostatic reference intervals in pregnancy. Thromb Haemost 2010;103:718-27.

24. Abid Memon H, Safdar Z, Goodarzi A. Use of extracorporeal membrane oxygenation in postpartum management of a patient with pulmonary arterial hypertension. Case Rep Pulmonol 2018;2018:7031731.

25. Ye J, Chen JY, Xu N, Wu B, Wang ZP, Xu HY, et al. Bilateral lung transplantation after caesarean section in pregnancy with severe pulmonary arterial hypertension: a case report. Medicine (Baltimore) 2019;98:e18109.

26. Ngatchou W, Ramadan AS, Van Nooten G, Antoine M. Left tilt position for easy extracorporeal membrane oxygenation cannula insertion in late pregnancy patients. Interact Cardiovasc Thorac Surg 2012;15:285-7.

27. Memon HA, Safdar Z. Use of extracorporeal membrane oxygenation in postpartum management of a patient with $\mathrm{PAH}$. Chest 2016;150(4 Suppl):1220A.

28. Thorne S, MacGregor A, Nelson-Piercy C. Risks of contraception and pregnancy in heart disease. Heart 2006;92:1520-5.

29. Phoophiboon V, Jaimchariyatam N, Srimahachota S, Sirinawin C. Successful multimodality management of severe pulmonary arterial hypertension during pregnancy with VA-ECMO and atrial septostomy using stent. BMJ Case Rep 2019;12:e231916.
30. Rubin LJ. Primary pulmonary hypertension. Chest 1993;104: 236-50.

31. Bonnin M, Mercier FJ, Sitbon O, Roger-Christoph S, Jaïs X, Humbert M, et al. Severe pulmonary hypertension during pregnancy: mode of delivery and anesthetic management of 15 consecutive cases. Anesthesiology 2005;102:1133-7.

32. Monagle J, Manikappa S, Ingram B, Malkoutzis V. Pulmonary hypertension and pregnancy: the experience of a tertiary institution over 15 years. Ann Card Anaesth 2015;18:153-60.

33. Uebing A, Steer PJ, Yentis SM, Gatzoulis MA. Pregnancy and congenital heart disease. BMJ 2006;332:401-6.

34. Liu S, Liston RM, Joseph KS, Heaman M, Sauve R, Kramer MS, et al. Maternal mortality and severe morbidity associated with low-risk planned cesarean delivery versus planned vaginal delivery at term. CMAJ 2007;176:455-60.

35. Hemnes AR, Kiely DG, Cockrill BA, Safdar Z, Wilson VJ, Al Hazmi M, et al. Statement on pregnancy in pulmonary hypertension from the Pulmonary Vascular Research Institute. Pulm Circ 2015;5:435-65.

36. Wong PS, Constantinides S, Kanellopoulos V, Kennedy CR, Watson D, Shiu MF. Primary pulmonary hypertension in pregnancy. J R Soc Med 2001;94:523-5.

37. Meng ML, Landau R, Viktorsdottir O, Banayan J, Grant T, Bateman B, et al. Pulmonary hypertension in pregnancy: a report of 49 cases at four tertiary North American sites. Obstet Gynecol 2017;129:511-20.

38. Weeks SK, Smith JB. Obstetric anaesthesia in patients with primary pulmonary hypertension. Can J Anaesth 1991;38:814-6.

39. Martin JT, Tautz TJ, Antognini JF. Safety of regional anesthesia in Eisenmenger's syndrome. Reg Anesth Pain Med 2002;27:50913.

40. McMillan E, Martin WL, Waugh J, Rushton I, Lewis M, Clutton-Brock T, et al. Management of pregnancy in women with pulmonary hypertension secondary to SLE and anti-phospholipid syndrome. Lupus 2002;11:392-8.

41. Tamhane P, O'Sullivan G, Reynolds F. Oxytocin in parturients with cardiac disease. Int J Obstet Anesth 2006;15:332-3.

42. Weiss BM, Zemp L, Seifert B, Hess OM. Outcome of pulmonary vascular disease in pregnancy: a systematic overview from 1978 through 1996. J Am Coll Cardiol 1998;31:1650-7.

43. Agerstrand C, Abrams D, Biscotti M, Moroz L, Rosenzweig EB, D'Alton M, et al. Extracorporeal membrane oxygenation for cardiopulmonary failure during pregnancy and postpartum. Ann Thorac Surg 2016;102:774-9.

44. Parissis JT, Paraskevaidis I, Bistola V, Farmakis D, Panou F, Kourea K, et al. Effects of levosimendan on right ventricular 
function in patients with advanced heart failure. Am J Cardiol 2006;98:1489-92.

45. Kerbaul F, Rondelet B, Motte S, Fesler P, Hubloue I, Ewalenko $\mathrm{P}$, et al. Effects of norepinephrine and dobutamine on pressure load-induced right ventricular failure. Crit Care Med 2004;32:1035-40.

46. Eichhorn EJ, Konstam MA, Weiland DS, Roberts DJ, Martin TT, Stransky NB, et al. Differential effects of milrinone and dobutamine on right ventricular preload, afterload and systolic performance in congestive heart failure secondary to ischemic or idiopathic dilated cardiomyopathy. Am J Cardiol 1987;60:132933.

47. Cheung PY, Barrington KJ. The effects of dopamine and epinephrine on hemodynamics and oxygen metabolism in hypoxic anesthetized piglets. Crit Care 2001;5:158-66.

48. Schreuder WO, Schneider AJ, Groeneveld AB, Thijs LG. Effect of dopamine vs norepinephrine on hemodynamics in septic shock: emphasis on right ventricular performance. Chest 1989;95:1282-8.

49. Kim H, Cho YH. Role of extracorporeal cardiopulmonary resuscitation in adults. Acute Crit Care 2020;35:1-9.
50. Ko RE, Chung CR, Yang JH, Jeon K, Suh GY, Oh SY, et al. Use of extracorporeal membrane oxygenation in postpartum patients with refractory shock or respiratory failure. Sci Rep 2021;11:887.

51. Moore SA, Dietl CA, Coleman DM. Extracorporeal life support during pregnancy. J Thorac Cardiovasc Surg 2016;151:1154-60.

52. Humbert M, Sitbon O, Simonneau G. Treatment of pulmonary arterial hypertension. N Engl J Med 2004;351:1425-36.

53. Galiè N, Humbert M, Vachiery JL, Gibbs S, Lang I, Torbicki A, et al. 2015 ESC/ERS guidelines for the diagnosis and treatment of pulmonary hypertension: The Joint Task Force for the Diagnosis and Treatment of Pulmonary Hypertension of the European Society of Cardiology (ESC) and the European Respiratory Society (ERS): endorsed by: Association for European Paediatric and Congenital Cardiology (AEPC), International Society for Heart and Lung Transplantation (ISHLT). Eur Heart J 2016;37:67-119.

54. Famuyide AO, Hopkins MR, El-Nashar SA, Creedon DJ, Vasdev GM, Driscoll DJ, et al. Hysteroscopic sterilization in women with severe cardiac disease: experience at a tertiary center. Mayo Clin Proc 2008;83:431-8. 